\title{
Investment and Expropriation under Oligarchy and Democracy in a Heckscher-Ohlin World*
}

\author{
Facundo Albornoz \\ University of Birmingham \\ Sebastian Galiani \\ Washington University in St. Louis \\ Daniel Heymann \\ CEPAL and University of Buenos Aires
}

August 6, 2009

\begin{abstract}
We study the incentives to expropriate foreign capital under democracy and oligarchy. We model a two-sector small open economy where foreign investment triggers Stolper-Samuelson effects through reducing exporting costs. We show how incentives to expropriate depend on the distributional effects of the investment and on how these affect the interests of the group in power. How investment affects the incomes of the different groups in society depends on the sectors where these investments are undertaken and on structural features of the economy such as factor intensities. We characterize expropriation equilibria and show that if investment is undertaken in the sector that uses labor less intensively; democracies are generally more prone to expropriate. This result provides one possible rationalization for the wave of expropriations in Latin America under governments with a broad popular base during the 20th Century.
\end{abstract}

\begin{abstract}
Keywords: expropriation; political regimes; democracy; oligarchy; foreign investments; Stolper-Samuelson.

JEL Classification: D72; D74; H71; 015; P16.
\end{abstract}

${ }^{*}$ We are grateful for funding from the ESRC (RES-062-23-1360). 


\section{Introduction}

There is an established consensus that attracting foreign direct investment (FDI) is a catalyst for economic development. Despite this consensus, FDI in developing economies has historically been controversial in host countries. Unconditional support and extreme criticism, often focused on distributional effects, have been historically observed polar attitudes towards FDI in host countries. These sharply different views were reflected in concrete policies, which have ranged from active measures intended to attract and induce foreign investments to outright expropriation. In this paper, we investigate the incentives to expropriate foreign investments under democracy and oligarchy and emphasize the distributional effects of FDI. From this perspective, we show that them depend on how FDI affects the payoffs of the different members of society and how these groups are represented by the political organization of the country. In this line, our model shows that the expropriation risk associated with democracy or oligarchy depends on the sector favored by FDI and some structural characteristics of the economy such as specialization, factor intensity and substitutability.

International contracts are difficult to enforce and, therefore, the interaction between governments and foreign firms is apt to be particularly influenced by political considerations (Eaton and Gersovitz (1983)). Alternative political systems such as democracy or oligarchy are associated with different mechanisms for the resolution of domestic disagreements, and with different weights of the interests of social groups in the determination of policies. Those interests depend on the configuration of the economy. In this paper, we investigate the connection between foreign investment, expropriation risk and political regimes. For reasons explained below, we focus on a historically relevant set of cases characterized by investments in infrastructure.

The literature on property rights and political regimes offers no definitive answers on the effect of democratic institutions on expropriation risk. While Olson (1993)) and North and Weingast (1989) highlight that democratic in- 
stitutions reduce the expropriation risk of investment, ${ }^{1}$ Acemoglu (2008) emphasizes instead that the investments of the elites might be more secure under oligarchic rule than under democratic governance. Following this line of reasoning, if FDI benefits the economic interests of those elites it might be more secure in an oligarchic society than in a democratic one. We contribute to this debate by exploring how the distributional effects of foreign investment determine the incentives to expropriate foreign capital under different political organizations such as democracy and oligarchy.

The general idea is that the risk of expropriation of FDI will depend on how these investments affect the relative prices and factor remunerations of the social sectors represented by the political regime in force. To illustrate this point in a meaningful way to understand historical evidence of developing economies, we model the economic and political aspects of foreign investments in infrastructure. Foreign investment in infrastructure provides a useful focus for the analysis, since it concerns immobile investments of a type that can generate conflicts of interests between social groups that are differently represented by democracy and autocracy. When operated by foreigners, like in the case of railway investment, foreign infrastructure investment involves subtler incentives to expropriate. In this regard, we find conditions under which investment is under threat even by the regime that represents the sector that is relatively favored by the presence of foreign capital.

Our model emphasizes that the basic results of the theory of international trade -including, above all, the well-known theorem of Stolper and Samuelson (1941)- have an impact on whether, under what circumstances, and possibly in what way, different political regimens might choose to expropriate FDI. Nevertheless, these differences in behavior are predictable, and depend on the factor intensities of the different sectors of the economy, the sector in which the investment is undertaken and the type of government that rules the country. In this sense, our arguments in this paper contribute to a broader literature that emphasizes the role of trade on domestic political cleavages and domestic institutions (see for example, Cardoso and Faletto (1979) and Rogowski (1986,

\footnotetext{
${ }^{1}$ Jensen (2006) argues that this logic might also apply to the case of FDI.
} 
1987, 1989)).

The relevance of analyzing expropriation of foreign infrastructure investment goes beyond historical interest. Although expropriation of foreign investment has declined in past years, tensions still remain as expropriation can take subtler forms, such as regulatory risks or high levels of taxation, usually referred to as creeping expropriation. Interestingly, Schiffer and Weder (2000) find that infrastructure foreign investment in developing countries, involving more than US $\$ 150$ billion during the 1980's, is particularly at risk of expropriation, which stands in stark contrast to the rest of investment in developing countries only subject to the risk of creeping expropriation. ${ }^{2}$

A clear example of the connection between the distributional effects of foreign investment and the propensities to expropriate under different political regimes is offered by the wave of FDI in railroads that took place throughout the world, and particularly in Latin America, in the late 19th and early 20th centuries. ${ }^{3}$ Foreign investment in transport and food conservation technologies has been identified as a cause of the rise of Latin American inequality during the 19th century. According to Coatsworth (2005), the effect of concentration of land ownership in Latin America on the concentration of wealth and income was limited until the installation of railroads and the use of newly developed refrigeration techniques enhanced the opportunities for profitable land exploitation and raised land values.

In Argentina in the first part of the 20th century, to mention an example, the support for railroad investments companies tended to come from conservative segments, with interests linked to agricultural export activities, while opposition was expressed by groups closer to import-competing sectors, including urban industrial workers. Critical views complained not only on monopolistic behavior or political lobbying on the part of the foreign investors, but

\footnotetext{
${ }^{2}$ In a complementary analysis, Pinto and Pinto (2008) associate the treatment received by the FDI with the ideology of recently elected government. They find, for example, that left-leaning incumbents favor FDI in sectors intensive is labor.

${ }^{3}$ See among others, Summerhill (2006), Cortés Conde (1979) and Coatsworth (1979), for economic histories of these processes. Between 1870 and 1930, the length of railway tracks in service in Latin America went from practically zero to approximately 150000 kilometers; see Sanz Fernandez (1998).
} 
they also stressed specifically the disincentives that the railroads generated for sectors exposed to foreign import competition (see, among others, Scalabrini Ortiz, 1940). Those positions emerged in the debates related to the nationalization measures implemented in 1948 by the government of Perón, which had wide popular support, especially from industrial workers. This pattern was observed throughout Latin America, with nationalizations and reversals of FDI taking place as political power shifted from regimes backed by agricultural elites to governments that responded more to the interests of urban labor. This is observed in Colombia, México and Costa Rica where railways run either by North-American or British companies have been nationalized in 1963, 1970 and 1972 respectively. In other regions however, expropriation has been undertaken by non-democratic governments like in the cases of Morocco in 1963 or Tunisia in 1965, where French and Spanish companies were nationalized.

Our analysis builds on the traditional observation that governments typically express objectives biased towards the interests of certain social groups (see, for example, Acemoglu, Johnson, and Robinson (2005)). In this line, we derive different government strategies vis-a-vis foreign investment taking into account the consequences of alternative policies on the incomes of the owners of different factors of production, land and labor in this case.

We model the conflicting distributional impacts of investments such as railroads on the incomes of social groups in the context of a two-sector small open economy that gives rise to Stolper-Samuelson effects (Stolper and Samuelson (1941)). ${ }^{4}$ Both goods are internationally tradable, and are produced with land and labor. Landowners constitute the economic elite, holding the political power in an oligarchic society. Workers are the majority of the population and therefore exert their influence under democracy. Though producers are price takers in the world markets of both goods, the net price faced by suppliers of the exportable good is decreasing in transport costs, since the international

\footnotetext{
${ }^{4}$ An alternative channel through which FDI may generate inequalities and therefore different attitudes toward expropriation is the skill upgrading associated with foreign affiliate activities. See, for example, Blonigen and Slaughter (2001).
} 
price is received FOB, at the port. We assume that the ad-valorem transport cost of shipping the exportable good can be reduced through investments in infrastructure which, for historical reasons, we associate with building railroads (the analysis would clearly apply also to other investments in infrastructure with effects on the profitability of the exportable sector). We focus on situations where the domestic economy is unable to undertake such investments and therefore railway construction requires the intervention of foreign investors. With their high fixed costs and values of sunk capital, railways required large initial outlays. Therefore, the decision to construct and to operate a railroad meant that investors entertained the expectations of large and long-lived flows of revenues. ${ }^{5}$

In cases where the exportable good is land-intensive and the importable good is labor-intensive, a reduction in the cost of transporting the exportable good would benefit landowners and harm workers, as it follows from the Stolper-Samuelson theorem. In our model, the redistributive effect of the investment in infrastructure differentiates the interests of landlords and workers. $^{6}$ It is ease to recognize that the opposite would be the effect of foreign investment in labor-intensive sectors. This allows us to derive the treatment of property rights under different institutional arrangements, without assuming that a simple relation exists between the type of political regime and its incentives to expropriate. We consider different political organizations: oligarchies represent the interests of landowners and democracies those of workers. The objectives of the corresponding authorities are described simply as the maximization of the market real incomes of the preferred groups.

A first issue regards the incentives for expropriation perceived by a democracy and an oligarchy when the contractual price of the transport service has already been fixed. In order to study this question we characterize the deci-

\footnotetext{
${ }^{5}$ See Summerhill (2006).

${ }^{6}$ To the extend this effect generates a conflict between the elite and the workers, our paper contributes to a recent literature on the links between trade and social conflict. For example, Dal Bó and Dal Bó (2004) show that positive shocks in capital intensive sectors in situations where appropriation activities are labor-intensive exacerbate distributive conflict in society.
} 
sions of the agents (foreign investors and the government) with the transport price as a parameter. Thus, we can find the configurations (realized investment without expropriation, investment with expropriation and no investment) that emerge for different values of the transport fee. This leads to an analytically simple comparison of the incentives to expropriate under each regime. In the argument, an oligarchy would find it expropriation convenient when railway tariffs are high (thus generating a strong conflict of interest between the local landlord elite and the railroad enterprize), while the opposite holds for a democracy. Naturally, those incentives would be symmetrically different if the exportable goods transported by the railroad were labor intensive. The model suggests that the range of transport prices that induces expropriation is larger for democratic than for oligarchic governments. However, this does not imply that democracies are necessarily more prone to expropriate than oligarchies. In this context, as we indicated above, the answer would depend on the type of investment, on structural features like the factor intensities of activities that make use of the services and the prices charged for those services. ${ }^{7}$ This result is consistent with Bohn and Deacon (2000) who find that the relationship between investment and expropriation risk depends on the type of resource involved in the foreign investment.

The model also shows that expropriation might be induced by foreign investors. If oligarchies are in power, high transport prices provide incentives for expropriation, while increasing the expected revenues associated with the investment. This induces a trade-off from the point of view of the investors between higher but risky and lower but safer returns. We then study if, supposing that foreign investors have full bargaining power to determine the contractual price of the service, they may choose a price high enough that it would induce

\footnotetext{
${ }^{7}$ This type of analysis can easily be extended to other forms of political regimes. Consider, for example, colonialism as a form under which the home country of overseas investments avoids expropriation risks. Everything else equal, our analysis would suggest that colonial domination would be more likely to take place in countries receiving investments in exporting sectors of primary goods where the economic elite holds weak political power. This complements Frieden (1994) who reaches a similar conclusion by emphasizing that monitoring and enforcing property rights are more costly for foreign investment in extractive and agricultural sectors.
} 
expropriation by an oligarchy. We find that conditional on structural features of the economy (like the elasticity of land rents to product prices) it would be possible to reach an equilibrium where unsafe investment is a consequence of a tariff negotiation between the investor and the government, even in situations where the foreign investor is able to set the tariff unilaterally. The attraction of high present revenues may make unsafe investment preferred by the foreign investor to a state with lower current prices which would make a future landlord government unwilling to expropriate (see Haber, Razo, and Maurer (2003)). This result casts doubts on the commonsensical prescription according to which an expropriation-free environment is always needed for foreign investment to occur.

\section{The Model}

\subsection{Foreign Investment}

We model foreign infrastructure investment as railway investment. This captures different aspects of foreign investment: foreign capital is immobile and triggers distributional effects that depend on the sector where the investment in undertaken but involves costs to the sector favored by the investment.

\subsection{The Economic Structure}

We consider an infinite horizon economy where a continuum of individuals on the $[0,1]$ interval is divided between a proportion $L>\frac{1}{2}$ of workers and a fraction $1-L$ of landowners. In each period, every worker is endowed with one unit of labor, so that the total supply of labor in the economy is L. Similarly, each landowner is endowed with one unit of land, corresponding to total stock $T=1-L$.

The economy produces two tradable goods using labor and land, with different factor intensities. We denote the land intensive good by $X$ and the labor intensive good by $S$. Through the paper we consider an economy that is 
relatively abundant in land. This implies that this economy is a net exporter of X.

Producers solve:

$$
\max _{L_{X}, T_{X}} z A_{X} T_{X}^{1-\gamma_{X}} L_{X}^{\gamma_{X}}-w L_{X}-r T_{X}
$$

and

$$
\max _{L_{S}, T_{S}} p_{S} A_{S} T_{S}^{1-\gamma_{S}} L_{S}^{\gamma_{S}}-w L_{S}-r T_{S}
$$

where $w$ and $r$ are wages and rents, which are equalized between sectors due to perfect factor mobility. $A_{X}$ and $A_{S}$ represent total factor productivities in each sector. The output elasticity with respect to labor is denoted $\gamma_{X}$ in sector $X$ and $\gamma_{S}$ in sector $S ; z$ and $p_{S}$ are respectively the net prices faced by the producers of the goods $\mathrm{X}$ and $\mathrm{S}$, respectively. Price $p_{S}$ is determined in the international market; the net price $z$ results from the world price of good $X$, $p_{X}$, together with the transport costs faced by producers, which depend on the existence of the railroad and the tariff that it charges.

The railroad lowers the ransport cost of shipping good $X$, but has no direct effect on good $S{ }^{8}$ The unit cost per unit of $X$ of the existing alternative method of transportation is $\alpha$. We assume that the transport capacity (measured in terms of the maximum amount of good $X$ that can be transported at zero cost) is proportional to the magnitude of sunk investments in the service, denoted by $K$ (good $X$ serving as numeraire); the constant of proportionality, $\kappa$, indicates the capital stock required to transport a flow equal to a unit of good X. Clearly, a larger $\kappa$ means that the project is more expensive. The railroad charges a price $\varphi$ per unit of good transported. Therefore, if $p_{X}$ is the world price of good $X$, and asuming that the demand for transportation does not exceed capacity, the net price received by the producers of good $X$ would be:

\footnotetext{
${ }^{8}$ In fact, the railroad would, if anything, reduce the domestic price of $S$, which would reinforce the effects on production and wages/rents that we analyze in this paper.
} 


$$
z=\left\{\begin{array}{lll}
p_{X}(1-\varphi) & \text { if } & \text { railway } \\
p_{X}(1-\alpha) & \text { if } & \text { no investment }
\end{array}\right.
$$

\subsection{The Effect of the Railway}

Clearly, landowners would be interested in the railway if and only if the shipping cost is lower than using the alternative transport method $(\varphi<\alpha)$, so that the investment leads to an increase in $z$. Let $\widehat{z}>0$ be the proportional change in the net price change for a given international price due to the existence of the railroad. Equilibrium, zero-profit, conditions in industries $S$ and $X$ imply that $^{9}$ :

$$
\begin{aligned}
\widehat{z} & =\gamma_{X} \widehat{w}+\left(1-\gamma_{X}\right) \widehat{r} \\
0 & =\gamma_{S} \widehat{w}+\left(1-\gamma_{S}\right) \widehat{r}
\end{aligned}
$$

Rearranging terms we obtain:

$$
\begin{aligned}
\widehat{w} / \widehat{z} & \equiv\left(1-\gamma_{S}\right) /\left(\gamma_{X}-\gamma_{S}\right) \equiv \widehat{\gamma}_{1} \\
\widehat{r} / \widehat{z} & \equiv \gamma_{S} /\left(\gamma_{S}-\gamma_{X}\right)=\widehat{\gamma}_{2}
\end{aligned}
$$

It is clear that, if as assumed, $\gamma_{S}>\gamma_{X}$, then $\widehat{\gamma}_{1}<0$ and $\widehat{\gamma}_{2}>1$. Therefore, an increase in $z$ induces an unambiguous (in terms of both goods) fall in real wages, and an equally unambiguous rise in the real value of land rents. This is the well-known Stolper-Samuelson result.

We use equations (1) and (2) to determine the payoffs of workers and landloords after the railway is in place. First, we note that:

$$
\widehat{z}=\frac{z(A R W)-z(B R W)}{z(B R W)}=\frac{\alpha-\varphi}{1-\alpha} .
$$

\footnotetext{
${ }^{9}$ To facilitate the exposition, we treat the changes as if they were of infinitesimal magnitudes, and proceed to use linear approximations.
} 
Let $w(B R W)$ and $w(A R W)$ be the wage rates before and after the railway is set-up, where $w(A R W)=w(B R W)+\Delta w$. Define $r(B R W)$ and $r(A R W)$ in a similar way. The variations in payoffs levels are:

$$
\begin{aligned}
\Delta w & =\widehat{\gamma}_{1} \frac{\alpha-\varphi}{1-\alpha} w(B R W) \\
\Delta r & =\widehat{\gamma}_{2} \frac{\alpha-\varphi}{1-\alpha} r(B R W),
\end{aligned}
$$

which imply

$$
\begin{aligned}
w(A R W) & =\left[1-\left|\widehat{\gamma}_{1}\right| \frac{\alpha-\varphi}{1-\alpha}\right] w(B R W) \\
r(A R W) & =\left[1+\widehat{\gamma}_{2} \frac{\alpha-\varphi}{1-\alpha}\right] r(B R W) .
\end{aligned}
$$

Equations (3) and (4) indicate the effects of the railroad on factor prices. Here, $w(A R W)<w(B R W)$ and $r(A R W)>r(B R W)$. Note, however, that the opposite would be the case if the sector mainly served by the railroad was relatively labor intensive. Therefore, investments in infrastructure can clearly induce conflicts of interests between different factors, depending on the economic structure and the nature of the capital which is to be put in place.

\section{Investment and Expropriation}

We assume that the economy lacks the capital and technical resources required to undertake the necessary investments to build the railway, and that some sort of foreign knowledge is required to operate the project initially. This rules out the possibility of financing the investments with international loans, and identifies the project with a FDI enterprise. Building and starting the operation of the railway requires the involvement of a foreign investor who provides both the capital and technical knowledge. This fits well the case of 
British railway investment in countries like Mexico and Argentina, and that of US railway investments in Brazil.

By assumption, the railroad has no explicit operational costs. The investment is made instantaneously; when it has taken place, the railway company sets a price of transport services, which must satisfy the participation constraints of both the government (since this must authorize the investment) and the foreign investor. Once the railroad is in place, and after it has operated for one period at the price established initially, the government decides whether to expropriate or not. We consider two political regimes, which determine different possible objectives for the authorities. In the oligarchy, the government represents the interests of the landowners and, therefore, behaves in a way that maximizes their payoff. In a democracy, the government represents the median voter, a worker by assumption, and therefore, seeks to maximize the payoff of workers.

We treat the government as one player and the foreign investor as another player in a dynamic game. The government has the faculty to negotiate with the foreign investor the installation of the railway and later decide whether to expropriate it or not.We focus on Markov Perfect Equilibria where each optimal strategy derives from payoff-relevant states, characterized by the expropriation costs.

If the government decides to expropriate, the economy incurs a loss denoted by $\mu$ and assumed to be equally distributed among al the residents. ${ }^{10}$ We introduce uncertainty about the cost of expropriation and focus on the parameter space where expropriation is not always possible. That is, the cost of expropriation depends on the state of nature $\left(S_{t}^{s}\right)$. This captures the idea that large-scale political decisions of the sort require particular conditions regarding, for example, the coherence of attitudes and the relative strengths of the parties involved. ${ }^{11}$ We model this by considering two states: if $S_{t}^{s}=B$, then

\footnotetext{
${ }^{10}$ We assume the country suffers as a whole the consequences of expropriation since it might be difficult to impose targeted reprisals against some individuals. This avoids potential problems with free-riding behavior as discussed by Acemoglu and Robinson (2006) in the case of the cost of a revolution.

${ }^{11}$ There are alternative reasons to adopt this type of representation as, for example, the
} 
$\mu=\infty$ and expropriation is not possible; if, on the other hand, $S_{t}^{s}=G$, then $\mu<\infty$ and the government might be willing to pay the cost of expropriation. The probability that the social state is $G(B)$ is denoted by $\psi(1-\psi)$. The sequence of events in the dynamic game we consider here are as follows:

1. The price of the freight service is determined.

2. In the initial period, the foreign investor decides whether to invest $K$ units of resources in the project. If the decision is not to invest, the investor gets the returns given by the world interest rate, consumption takes place and the period ends.

3. The state $S_{t}^{s}$ is revealed.

4. If investment took place in the previous period, the local government, democratic or oligarchic, decides whether to expropriate or not. Expropriation is not reversible.

5. Production, consumption and trade take place.

6. If the government decided not to expropriate, Steps 3 to 5 are repeated with infinite horizon.

The implication of this timing structure is that the investment decision will take into account the possibility of expropriation in order to calculate the continuation values associated with each strategy. For most of the analysis we are going to consider the price of freight as exogenously given. This will allow for a characterization of the different equilibria of the expropriation game that provides a simple comparison of the different incentives to expropriate in democracy and autocracy. In the last part of the paper, we explore the determination of the freight price and obtain some surprising results on the attitudes of the foreign investor when facing expropriation risk.

"obsolescing bargain" hypothesis. As suggested by Kindeleberger (1969) and emphasized by Vernon (1971), the faculty to impose domestic conditions on existing foreign investment increases over time. In the limit, the host government can renege on initial agreements (as tariffs) and seize the control of the investment. 


\subsection{Expropriation}

We first consider the incentives for expropriation perceived by an oligarchy and a democracy when the contractual price of the transport service has already been fixed. We assume that any renegotiation of the contract entails a fixed cost for the government, so that in fact its choice variable is whether to expropriate or not. In a second step, we analyze the incentives to invest and we determine the relevant range of prices that generate the different types of equilibria of the dynamic game: investment with no expected expropriation, expropriable investment and no investment.

\subsubsection{Expropriation under Oligarchy}

Let $r(E)$ be the land rent after expropriation. Clearly, if the oligarchic government decides to expropriate, the market incomes of its constituents are maximized by setting the price of the service at zero: $\varphi=0$. Using equation (4), we then obtain:

$$
r(E)=\left(1+\widehat{\gamma}_{2} \frac{\alpha}{1-\alpha}\right) r(B R W) .
$$

We can now compute the continuation values (discounted expected net present values) for the elite in both cases: expropriation (E) and nonexpropriation (NE).

$$
\begin{aligned}
W^{E}(N E) & =\frac{r(A R W)}{1-\beta} \\
W^{E}(E) & =\frac{\psi}{1-(1-\psi) \beta}\left[\frac{r(E)}{1-\beta}+\frac{r(A R W)(1-\psi)}{\psi}-\mu\right]
\end{aligned}
$$

where $\beta$ is the discount factor.

We implicitly make some assumptions that need clarification. First, $\varphi$ remains, for the time being, exogenously given. Second, the railroad does not deteriorate over time and therefore its cost-reducing effect is permanent. We also assume that the railway functioning is independent on who is running it. 
This implies that, once in place, the railway may be run by foreign investors, democratic or autocratic governments without any additional cost. Finally, we do not consider the possibility of new foreign investments after expropriation.

Under oligarchy, expropriation takes place if $W^{E}(E)>W^{E}(N E)$. Using equations (5) and (6), this condition implies

$$
\frac{r(E)}{1-\beta}-\mu \geq \frac{r(A R W)}{1-\beta}
$$

This is an intuitive condition. The oligarchic government will choose expropriation if the state of the world alows it, if and only if the difference between the present value of the (infinite) flow of rents at zero transport cost exceeds the value of rents at the given transport price by more than the current costs that expropriation imposes on landlords.

After rearranging, this condition becomes:

$$
\varphi>\frac{\mu(1-\beta)(1-\alpha)}{r(B R W) \widehat{\gamma}_{2}} \equiv \varphi_{1 A}
$$

In the case of $\varphi>\varphi_{1 A}$, expropriation gains for the elite are large enough so that the oligarchic government would rather incur the cost $\mu$ and take over the railway.

\subsubsection{Expropriation under Democracy}

The democratic government will act in order to maximize the welfare of workers. When no expropriation takes place, the continuation value for workers is given by:

$$
W^{w}(N E)=\frac{w(A R W)}{1-\beta}
$$

Democratic expropriation may potentially take different forms in order to benefit workers. We consider the case in which expropriation implies eliminating the service that the investment provides to export activities, which would make wages increase to the pre-investment level. That is, the StolperSamuelson effects of the railroad would be entirely reversed by expropriation. 
We also assume that there is no market for expropriated capital. ${ }^{12}$ This assumption makes the incentive for expropriation rely exclusively on the factorprice effects and rules out other reasons for expropriation.

It is straightforward to show that the expected utility of the government (that is, that of the representative worker) after expropriation is:

$$
V^{w}(G)=\frac{w(B R W)}{1-\beta}-\mu
$$

On the other hand, the expected utility for the representative worker associated with non-expropriation is:

$$
V^{w}(B)=w(A R W)+\beta W^{w}(E)
$$

where $W^{w}(E)=\psi V^{w}(G)+(1-\psi) V^{w}(B)$ is the continuation value associated with the expropriation strategy. After using equations (8) and (9), $W^{w}(E)$ becomes:

$$
W^{w}(E)=\frac{\psi}{1-(1-\psi) \beta}\left[\frac{w(B R W)}{1-\beta}+\frac{(1-\psi) w(A R W)}{\psi}-\mu\right]
$$

Thus, the democratic government will expropriate whenever $W^{w}(E)>$ $W^{w}(N E)$, that is, when

$$
\frac{w(B R W)}{1-\beta}-\mu>\frac{w(A R W)}{1-\beta}
$$

This condition has a similar straightforward interpretation as in the case of the oligarchic government. The corresponding condition for $\varphi$ is:

$$
\varphi<\alpha-\frac{(1-\beta)(1-\alpha) \mu}{\left|\widehat{\gamma_{1}}\right| w(B R W)} \equiv \varphi_{1 D}
$$

\footnotetext{
${ }^{12}$ We could assume as well that expropriated capital can somehow be sold. If the proceeds are redistributed, this would generate an additional incentive to expropriate under democracy. The magnitude of this additional motive depends on how specific the railway capital is and on how large is the population of workers relative to the capital invested $(K)$.
} 


\subsubsection{Democracy versus Oligarchy}

In this section we compare the incentives to expropriate under Democracy and Oligarchy. The first step consists in identifying conditions for expropriation to occur under both regimes. Notice first that a feasible railway requires $\varphi<\alpha$. We assume that this holds. The question now is to study the relative magnitude of the expropriation bounds, $\varphi_{1 A}$ and $\varphi_{1 D}$. In principle, both cases are possible: $\varphi_{1 A} \geq \varphi_{1 D}$ or $\varphi_{1 A}<\varphi_{1 D}$. To characterize such cases, observe that both thresholds depend on $\alpha$ in an opposite way: while $\varphi_{1 A}$ decreases in $\alpha, \varphi_{1 D}$ increases in $\alpha$. This implies that $\varphi_{1 D}$ is higher than $\varphi_{1 A}$ for sufficiently high levels of $\alpha$. More specifically, this is true for

$$
\frac{\alpha}{1-\alpha}>\mu(1-\beta)\left[\frac{1}{\left|\hat{\gamma_{1}}\right| w(B R W)}+\frac{1}{\hat{\gamma}_{2} r(B R W)}\right] .
$$

When inequality (11) holds, it follows that:

1. if $\varphi<\varphi_{1 A}$, only democracies expropriate;

2. if $\varphi \in\left[\varphi_{1 A}, \varphi_{1 D}\right]$, both democracies and autocracies expropriate;

3. if $\varphi>\varphi_{1 D}$, only oligarchies expropriate.

When inequality (11) does not hold, it follows that:

4. if $\varphi<\varphi_{1 D}$, only democracies expropriate;

5. if $\varphi \in\left[\varphi_{1 D}, \varphi_{1 A}\right]$, neither democracies nor autocracies expropriate;

6. if $\varphi>\varphi_{1 A}$, only oligarchies expropriate.

The above cases capture important features of the link between expropriation and political regimes. Only democracies expropriate when $\varphi$ is sufficiently low (cases 1 and 4). This is due to the fact that a lower $\varphi$ implies a larger Stolper-Samuelson effect and therefore the railway is very profitable for landowners and very negative for the interests of the workers. When the transportation price is sufficiently high, only oligarchies expropriate (cases 3 and 6). 
From the point of view of the workers, the magnitude of the Stolper-Samuelson effect does not compensate the expropriation cost. For the oligarchy, however, the incentive to expropriate is strong as they could raise the land returns considerably by lowering the transportation price. Naturally, low values of $\alpha$ reduce the potential size of the Stolper-Samuelson effects. If $\alpha$ is sufficiently low, there are cases under which expropriation never occurs.

We find that an oligarchy finds it convenient to expropriate when railway tariffs are high (thus generating a strong conflict of interest between the local landlord elite and the railroad enterprise), while the opposite holds for a democracy. However, and interestingly enough for our main argument, note that these incentives would be symmetrically different if the exportable good transported by the railroad was labor intensive.

Even though the previous analysis shows that expropriation may occur under both political regimes, under the assumptions made, we find that:

Proposition 1 Democracies tend to expropriate for a larger set of transportation prices than Oligarchies.

Proof $\alpha-\varphi_{1 A}<\varphi_{1 D}$ implies $\alpha-\frac{\mu(1-\alpha)(1-\beta)}{\hat{\gamma}_{2} r(B R W)}<\alpha-\frac{\mu(1-\alpha)(1-\beta)}{\left|\hat{\gamma}_{1}\right| w(B R W)}$ which requires $\hat{\gamma}_{2} r(B R W) T>\left|\hat{\gamma}_{1}\right| w(B R W) L$ to be satisfied. Observe that this implies $\frac{T_{S}}{T}<\frac{L_{S}}{L}$, which is always satisfied by assumption.

It is also worth investigating how changes in $\mu$ affect the incentives to expropriate under oligarchy and democracy. This would give an indication on how the incentives scale with the penalties for expropriation.

Computing $\frac{\partial \varphi_{1 A}}{\partial \mu}$ and $\frac{\partial \varphi_{1 D}}{\partial \mu}$, we obtain

$$
\begin{gathered}
\frac{\partial \varphi_{1 A}}{\partial \mu}=\frac{(1-\beta)(1-\alpha)}{r(B R W) \hat{\gamma_{2}}} \\
\frac{\partial \varphi_{1 D}}{\partial \mu}=-\frac{(1-\beta)(1-\alpha)}{w(B R W)\left|\hat{\gamma_{1}}\right|}
\end{gathered}
$$

Clearly, the expropriation cost reduces the incentives to expropriate in both regimes. Observe that $\frac{T_{S}}{T}<\frac{L_{S}}{L}$ implies that $\left|\frac{\partial \varphi_{1 D}}{\partial \mu}\right|>\frac{\partial \varphi_{1 A}}{\partial \mu}$ and therefore that 
democracies are, although keener to expropriate, more sensitive to changes in the expropriation costs.

\subsection{The Investment Decision}

The foreign investor has to decide whether to invest or not. We consider the railway project as a lump-sum investment of size $K$. This entitles the investor to get revenues from transporting good $X$ by charging a unit price $\varphi$. As the railway increases production in sector $X$, railway revenues depend on the volume of output after the railway is in place $\left(X^{A R W}(\varphi)\right)$. We show in the appendix that

$$
X^{A R W}(\varphi)=\left(1+\epsilon \frac{\alpha-\varphi}{1-\alpha}\right) X^{B R W}(\varphi)
$$

Where $\epsilon=\frac{\widehat{y X}}{\widehat{z}}$ is the output elasticity of the agricultural good with respect to the net price $z$ and $X^{B R W}(\varphi)$ is the level of production of $X$ before the railway has been built.

The opportunity cost of investing in the railway is given by the world interest rate $i^{*}$. To calculate the continuation value for the investor we need to consider two cases: when $\varphi$ is such that the government will expropriate as soon as the state of the world alllows it (i.e. $S_{t}^{s}=G$ ), and when expropriation will never take place $\left(S_{t}^{s}=B\right)$.

When expropriation is certain in one of the states of the world, the value of the project for the investor is:

$$
W^{F I}(E)=\psi V^{F I}(G)+(1-\psi) V^{F I}(B)
$$

Where, given that expropriation drives to zero the revenues, the value of the project for the investor in that state is: $V^{F I}(G)=0$. When expropriation does not take place (i.e. while $S_{t}^{s}=B$ ), the foreign investor gets an income per period $\varphi X^{A R W}(\varphi)$ and therefore the value of the project is:

$$
W^{F I}(E)=\frac{(1-\psi) \varphi X^{A R W}(\varphi)}{1-(1-\psi) \beta}
$$


The railway is a better investment than the opportunity cost if:

$$
\varphi X^{A R W}(\varphi)\left(\frac{1-\psi}{1-(1-\psi) \beta}\right) \geq \frac{i^{*} K}{1-\beta}
$$

This is the investment constraint. The condition can be reformulated to highlight the role of the parameter $\kappa$, which measures the volume of investment required per unit of transport capacity: $\kappa=\frac{K}{X^{A R W}}$. Clearly, a lower $\kappa$ implies a cheaper railway infrastructure per unit of services supplied. Rearranging equation (13), we obtain:

$$
\kappa \leq \frac{\varphi}{i^{*} \Omega}
$$

where $\Omega=\frac{1-(1-\psi) \beta}{(1-\psi)(1-\beta)}$. The expected return on investment exceeds the opportunity cost if the invested capital per unit of services is lower than the expected present value of prices charged, suitably discounted (taking into account the possibility of expropriation). This defines a bound for the price of services in order for the project to be undertaken in the case there is expropriation risk:

$$
\varphi_{2}=i^{*} \Omega \kappa
$$

Clearly, a lower value of $\kappa$ reduces the minimum price acceptable to investors. When expropriation will never take place, investment is undertaken if

$$
\kappa \geq \frac{\varphi}{i^{*}}
$$

which establishes the bound for profitable investment under no expropriation:

$$
\varphi_{3}=i^{*} \kappa
$$

Notice that $\Omega>1$; thus $\varphi_{3}<\varphi_{2}$, which states the obvious but reassuring result that safe investment is likelier than expropriable investment.

We have identified the existence of values of $\varphi$, both for safe and expro- 
priable investments, which make the project more attractive for the investor than the alternative placement of the resources in international capital markets. The question is now if the investor would sometimes choose to undertake the project and, if able to determine the price unilaterally, would set it at a level that would make the project subject to future expropriation

We analyze the case of Oligarchy. ${ }^{13}$ The first thing is to establish a tradeoff between maximizing earnings under no expropriation and incurring an expropriation risk. This is done by showing that single-period revenues of the railroad are maximized at a price higher than the one $\left(\varphi_{1 A}\right)$ that would induce the government to expropriate if it had the chance to choose. This means that we need to investigate whether there exists $\varphi$ such that $\varphi X^{A R W}\left(\varphi>\varphi_{1 A}\right)>\varphi_{1 A} X^{A R W}\left(\varphi_{1 A}\right)$. Solving this implies:

Proposition 2 There exist levels of the transport tariff

$$
\varphi>1-\alpha(1+\epsilon)-\frac{\mu(1-\alpha)(1-\beta)}{r(B R W) \hat{\gamma}_{2}} \equiv \varphi^{*}
$$

such that, while the investor controls the project, the revenues generated when the investment is subject to expropriation are larger than those that would accrue at a price that makes the project immune to expropriation risk.

$$
\begin{aligned}
& \text { Proof } \varphi X\left(\varphi>\varphi_{1 A}\right)-\varphi_{1 A} X\left(\varphi_{1 A}\right)>0 \text { implies } \\
& \varphi\left[1+\epsilon \frac{\alpha}{1-\alpha}\right]-\frac{\varphi^{2}}{1-\alpha}-\frac{\mu(1-\alpha)(1-\beta)}{r(B R W) \hat{\gamma_{2}}}\left[1+\epsilon\left(\frac{\alpha}{1-\alpha}-\frac{\mu(1-\beta)}{r(B R W) \hat{\gamma_{2}}}\right)\right]>0
\end{aligned}
$$

This has two solutions:

1. $\frac{\mu(1-\beta)(1-\alpha)}{r(B R W) \hat{\gamma}_{2}}$

2. $1-\alpha(1+\epsilon)-\frac{\mu}{r(B R W) \hat{\gamma_{2}}}[(1-\alpha)(1-\beta)]$

It is immediate that only 2 satisfies $\varphi X\left(\varphi>\varphi_{1 A}\right)>\varphi_{1 A} X\left(\varphi_{1 A}\right)$.

\footnotetext{
${ }^{13}$ The analysis for Democracy is similar and it is available upon request.
} 
This result suggests that expropriation may potentially be induced by the foreign investor if this has the power of choosing the tariff. We explore further this possibility in section 4 .

\subsection{Alternative policies}

The previous analysis showed that democratic governments may expropriate foreign investments as a reaction to their distributional effects, in a very stylized model that illustrated in a simple fashion some basic conflicts of interests among groups in society that might be triggered by FDI. Such conflicts are central elements in defining the incentives that determine the behavior of different types of governments regarding the investments. In the real world, however, the Stolper-Samuelson distributive effects may induce other policy responses, for example through taxes on foreign trade, an instrument that was widely used in some countries, particularly in Latin America, as means to raise the incomes of urban workers. In the setting that we have considered, trade policies would shift the demand for the services of the railroad, and consequently would modify the profitability of the activity, and the incentives of the government and the investors. In certain specifications of the problem, if a government (in our case, a democratic regime) implements measures that restrict exports, a possible outcome may be that the investors choose to withdraw from the business, resulting in a nationalization that would not entail outright expropriation as creeping expropriation. ${ }^{14}$

Consider for example the case of an export tax $\tau^{X}=\alpha-\varphi$ that pushes $z$ back to the pre-investment level.It is straightforward from equations (3) and (4) to see that market wages and land rents return to w(BRW) and r(BRW) respectively. However, the redistributive effects of this measure go beyond those of direct expropriation as the government collects tax revenues (equal to $\left.\tau^{X} X(B R W)\right)$ that can be redistributed among workers.

For the foreign investor, the effect of export taxes for a given transport price is a reduction of profits due to a drop in the volume of the freight to be

\footnotetext{
${ }^{14}$ This form of pressure on foreign investment is also associated with the phenomena of "forced divestment" (??).
} 
transported, given by the Rybcinski-type expression (20) in appendix A. The level of activity of the railroad would then be low relative to the size of the investment put in place $(K)$. This would reduce profits, but would not make the investors unwilling to operate the project when the investment is sunk and running costs are proportional to traffic. However, if the operation requires fixed costs in proportion to $K$ (for example, in order to maintain rails and stations), such costs may be sufficiently high compared with the revenues at the new level of traffic so as to eliminate current profits. Here, the investors would opt for abandoning the activity, or run down the infrastructure until the project effectively shuts down. This scenario of a nationalization seems to match with instances like the transfer of Argentine railroads to the government during the presidency of Perón (see, among others, García Heras (1994)).

If setting taxes on foreign trade does not entail for the governments the costs associated with expropriation, the likelihood of such policies would be higher than that a direct takeover. Then, the prospect of the application of such taxes may operate as a strong deterrent of investment. An analysis of the investment decision when the government's policy instrument consists of export taxes is presented in Appendix C.

Another variant of the problem would appear in the case of expropriation by a democratic government, which could gain control over the railroads, reset the tariff $\varphi$ and redistribute railway revenues among workers. This strategy would operate through the Stolper-Samuelson effect and also through the returns on the investment. Regarding the price-setting choice of the government, it would weigh the effects on factor returns together with the revenues from the transport monopoly. Intuitively, the price would be set above the profit maximizing monopoly price (if that price is strictly lower than $\alpha$ ), and below the level that makes the use of the railway prohibitive for producers of good $A$. In any case, including a potential margin of benefits through redistributed revenues would amplify incentives to appropriate the project for a democracy. 


\subsection{Equilibrium Characterization}

We have identified the investment and expropriation constraints. These are determined by wages and rents levels, which are themselves functions of the tariff associated with the railway. We can therefore find solutions for a given $\varphi$ and state the corresponding expropriation behavior of democracies and oligarchies.

We need to show the existence of tariffs allowing for railway investment. As the break even thresholds under no expropriation risk $\left(\varphi_{3}\right)$ and without that risk $\left(\varphi_{2}\right)$ are such that $\varphi_{3}<\varphi_{2}$, the potential existence of both safe and expropriable investments requires the existence of values of $\varphi$ such as $\varphi \in\left[\varphi_{2}, \alpha\right]$. This is equivalent to show that $\varphi_{2}<\alpha$. The following lemma states the condition for this possibility.

Lemma 1 The possibility of railway investment requires the following condition to hold

\section{Condition 1}

$$
\kappa \leq \frac{\alpha}{i^{*} \Omega}
$$

Proof It immediately follows from inspecting $\varphi_{2}<\alpha$ using equation (14).

This result involves an interesting implication. We can interpret $\kappa^{-1}$ as a measure of railway efficiency. Therefore, investment requires a minimum level of efficiency. Simple comparative statics show that how binding is such requirement depends on investment opportunities abroad $\left(i^{*}\right)$, the cost of alternative transport methods $(\alpha)$, political stability, captured by the probability of social states in which expropriation is possible $(\psi)$ and the discount factor $(\beta) .{ }^{15}$

Proposition 3 When Condition 1 holds, there exists $\varphi \in\left(\varphi_{3}, \alpha\right)$ such that, given the intervals:

\footnotetext{
${ }^{15}$ Note that both $\psi$ and $\beta$ are implicit in $\Omega$.
} 


$$
\begin{aligned}
& Z_{1}=\left\{\varphi \in X: \varphi \leq \varphi_{1 D} \wedge \varphi \leq \varphi_{1 A}\right\} \\
& Z_{2}=\left\{\varphi \in X: \varphi>\varphi_{1 D} \wedge \varphi \geq \varphi_{1 A}\right\} \\
& Z_{3}=\left\{\varphi \in X: \varphi \leq \varphi_{1 D} \wedge \varphi \geq \varphi_{1 A}\right\} \\
& Z_{4}=\left\{\varphi \in X: \varphi \geq \varphi_{1 D} \wedge \varphi \leq \varphi_{1 A}\right\}
\end{aligned}
$$

Then:

- $\varphi \in Z_{1}$ implies that expropriation only occurs under democracy;

- $\varphi \in Z_{2}$ implies that expropriation only occurs under oligarchy;

- $\varphi \in Z_{3}$ implies that both types of government expropriate;

- $\varphi \in Z_{4}$ implies that neither a democratic government nor an autocratic government expropriate.

Proof See Appendix B where we define the conditions for non-emptiness of $Z_{1}$ to $Z_{4}$.

This result summarizes the previous analysis and demonstrates the existence of cases $Z_{1}$ to $Z_{4}$.

So far we have treated the tariff as exogenous. As suggested by proposition 2 , we turn now to investigate whether tariffs yielding to expropriation can be imposed by the foreign investor in a negotiation with the government.

\section{Expropriation risk induced by the foreign investor}

We consider now the case in which freight prices are determined through a negotiation between the government and the investor. A variety of outcomes 
can emerge depending on the respective bargaining powers, the value of expropriation costs, the political regime and the economic structure. The possibility of both expropriable and safe investments amplifies the number of candidate equilibria. Instead of fully characterizing all these cases, we focus on situations where expropriation is an outcome in the case where the bargaining power lies fully with the investor.

Given the configuration of the economy, a democratic government would be a tougher negotiator than the one representing oligarchic interests because of the negative Stolper-Samuelson effect on wages. ${ }^{16}$ The landlord group, in contrast, would welcome railway investments per se as means to raise their rents. We focus then on the case of an oligarchy.

The key question is whether expropriation is an equilibrium outcome in situations where the oligarchic government negotiates with the investor. Consider the case of Nash bargaining. Any incentive compatible price resulting from negotiation must satisfy the conditions given in Proposition 3. This implies, for example, that an incentive compatible tariff yielding an equilibrium with expropriation has to be greater than $\varphi_{2}$ (so that the investor is willing to invest) and also higher than $\varphi_{1 A}$ (so that the government chooses to expropriate when the opportunity arises).

We need to establish first when the government is willing ex ante to accept a deal with the investor yielding expropriation in the future. If the railroad is to be built, the landlord group must obtain a greater payoff than the one resulting in the absence of the railway, that is:

$$
\frac{\psi}{1-(1-\psi) \beta}\left[\frac{r(X)}{1-\beta}+\frac{r(A R W)(1-\psi)}{\psi}-\mu\right] \geq \frac{r(B R W)}{1-\beta}
$$

which is satisfied for

\footnotetext{
${ }^{16} \mathrm{~A}$ democratic government may still be interested in the railway if expropriation gains are expected to be sufficiently high. However, this would require benefits accruing from running the railroad (through re-distributed incomes) and not only through a reversal of the Stolper-Samuelson effect.
} 


$$
\varphi<\alpha\left(\frac{1-(1-\psi) \beta}{(1-\psi)(1-\beta)}\right)-(1-\alpha)\left(\frac{\psi}{1-\psi} \frac{\mu}{\hat{\gamma_{2}} r(B R W)}\right) \equiv \varphi_{1 A}^{\prime}
$$

The upper bound $\varphi_{1 A}^{\prime}$ depends positively on $\alpha$, because a higher transport cost before the railway increases the payoff for the landlords of having the railroad; the negative dependence on the expropriation cost $\mu$ derives from the fact that, with higher expropriation costs, the government requires a larger payoff in order to find the railroad project acceptable. An equilibrium involving expropriation requires $\varphi_{1 A}<\varphi_{1 A}^{\prime}$ (i.e., the maximum tariff not generating expropriation incentives must be lower than the maximum price for which the government would accept the railroad under a transport price that will induce expropriation). Otherwise, any outcome of the negotiation allowing the railway will imply no future expropriation. The condition for $\varphi_{1 A}<\varphi_{1 A}^{\prime}$ is:

$$
\mu<\frac{\alpha r(B R W) \hat{\gamma}_{2}}{(1-\alpha)(1-\beta)} \equiv \mu_{1} \quad \text { (Expropriation Condition) }
$$

A low expropriation cost relative to the transport costs saved by the railroad raises the incentives of the government to take over the railroad when the opportunity emerges, and it increases the value of having the railroad built given future expropriation. Observe as well that $\mu_{1}$ is increasing in $\hat{\gamma}_{2}$. This means that a higher price elasticity of land rents implies higher benefits from expropriation, which is reflected in both a lower $\varphi_{1 A}$ and a higher $\varphi_{1 A}^{\prime}$.

A simple representation of the bargaining scenario results from looking at the extreme cases where one of the participants can impose its preferred price subject to an incentive compatibility constraint for the other party. We are interested in cases where the foreign investor can induce her preferred tariff. $^{17}$ To make calculations simpler, we assume that the revenues from the

\footnotetext{
${ }^{17}$ Alternatively, consider this brief sketch of the case where the oligarchic government can impose the price that will make the foreign investor just willing to build the railroad. Since the landlords's payoff decreases in the price, the government will choose between the two minimum prices that will induce investment, without expropriation in one case, and with expected expropriation in the other. We know from our discussion above that these tariffs are $\varphi_{3}$ for the safe investment, and $\varphi_{1 A}$, for expropriable investment. Thus, the
} 
railroad are increasing with the tariff in the range between 0 and $\alpha$, that is, the elasticity of the traffic with respect to the price is less than unity in that range. This simply requires $\epsilon$ to be greater than $\frac{1-\alpha}{\alpha}$ (i.e., a sufficiently high output elasticity with respect to the net price of the exportable good). Then, the investor will choose $\varphi_{1 A}$ in the case of safe investment and $\min \left\{\alpha-\varsigma, \varphi_{1 A}^{\prime}\right\}$ for $\varsigma$ infinitesimally low in the case of expropriable investment.

The investor prefers imposing a high tariff which makes the project liable for future expropriation when

$$
W^{F I}\left(N X, \varphi_{1 A}\right)<W^{F I}\left(X, \min \left\{\alpha-\varsigma, \varphi_{1 A}^{\prime}\right\}\right)
$$

that is

$$
\frac{\varphi_{1 A} X^{A R W}\left(\varphi_{1 A}\right)}{1-\beta}<\frac{(1-\psi) \min \left\{\alpha-\varsigma, \varphi_{1 A}^{\prime}\right\} X^{A R W}\left(\min \left\{\alpha-\varsigma, \varphi_{1 A}^{\prime}\right\}\right)}{1-(1-\psi) \beta}
$$

It can be shown that sufficiently low expropriation costs would make the foreign investor choose a tariff associated with expropriation. We develop in the appendix $\mathrm{D}$ the inequality in equation 18 for both $\varphi_{1 A}^{\prime} \geq \alpha$ and $\varphi_{1 A}^{\prime}<\alpha$. In both cases, equation 18 is clearly satisfied for $\mu=0$. Observe that both sides of (18) are continuously differentiable with respect to $\mu$. As the left hand side is increasing in $\varphi_{1 A}$, it is increasing in $\mu$ too. This implies that expropriation is chosen by investors for sufficiently low values of $\mu$ (i.e. for $\mu<\bar{\mu} \in(0, \infty])$. Obviously, this condition is more likely to be satisfied for low levels of $\psi$ which means that this strategy is likelier in relatively stable social states where expropriation is unlikely.

Let us summarize the analysis by the following proposition:

\section{Proposition 4 (Expropriation with prices chosen by the investor)} An equilibrium with expropriable investment is a consequence of the foreign investor's choice for

government will choose according to the comparison between the values of $W^{E}\left(N X, \varphi_{3}\right)$ and $W^{N E}\left(X, \varphi_{1 A}\right)$. 
- $\mu<\min \left\{\mu_{1}, \bar{\mu}\right\}$

For low expropriation costs, the investor prefers obtaining high revenues up to the moment when expropriation takes place instead of lowering the tariff enough to conserve the permanent right to exploit the railroad; a similar result would hold for an impatient investor. Higher values of $\mu$ eliminate the expropriation equilibrium and, at the same time, they increase the ability of the investor to extract the rents from the project if it has the bargaining power on its side.

\section{Concluding remarks}

We have studied the incentives to expropriate foreign capital in a setup where government incentives vary according to the actual effects of investments on the incomes of different social groups, and with the weights the authorities attach to the welfare of those groups. The attitudes toward FDI depend on the nature of the investments and the economic structure of the receiving country. Whether democracies are more or less prone to expropriation than oligarchies

depends crucially, but in a predictable way, on the type of investment considered and on structural features of the economy such as the factor intensities of activities that make use of the services provided by the investments in questio. Our analysis suggests that there needs not be an unambiguous relation between the type of the government and its behavior towards FDI. Therefore, the right question for empirical research does not seem to be whether democracies or other forms of governments are more prone to expropriation. A fuller and more concrete analysis may start from the proposition that governments typically express objectives biased towards the interests of certain social groups, and that large investment projects might have sizeable distributive effects among segments of the population in the host country.

Our analysis offers, for example, one plausible rationalization for the fact that mass democracies in Latin America during the XXth century were prone to nationalize FDI projects directed to the provision of services to the production of tradable goods controlled by agricultural elites. In the context studied, 
foreign investments, through Stolper-Samuelson effects, benefited landlords and hurt labor-intensive activities, thus tending to lower wages. Naturally, under oligarchic rule, those investments were desirable for the government, and were undertaken by foreign investors. Once the institutional framework of those investments was inherited by governments that put high weights on the interests of workers, incentives to expropriate emerged. This, however, is not an intrinsic characteristic of democracies, but results in particular configurations of economic interests associated with the comparative advantages of the countries. With different economic structures, democracies could have different incentives with respect to FDI projects that provide services to the production of exportable goods.

Another interesting result emerging from our analysis is that, conditional on structural features of the economy, it would be possible to reach equilibrium states where expropriable investment is a consequence of a price negotiation between the investor and the government, even in situations where the foreign investor is capable of setting that price unilaterally. The attraction of high revenues in no-expropriation states may make expropriable investment preferred by the foreign investor to a scenario with lower prices, which would make a future landlord government unwilling to expropriate. An implication of this result is that, under plausible circumstances, the assurance of no future expropriation is not necessarily a precondition for foreign investment but it is endogenously determined by the interaction between domestic governments and foreign investment.

We have concentrated on cases that would correspond to investments made at relatively early stages of economic development in economies like those of Latin America, where foreign investment tend to take place in sectors linked to foreign trade, and foster the interests of relatively homogenous local elites, whose economic activities are complementary with foreign capital or infrastructure. As an economy develops and diversifies, the complementaries and conflicts of interest become more intrincate. Social groups, and business sectors, in particular, can exploit their political influence to induce the government to undertake actions in their favor. Whether governments are more 
sensitive to lobbying under democracies or autocracies is a question that we leave open for future research.

\section{References}

Acemoglu, D. (2008): "Oligarchic versus democratic societies," Journal of the European Economic Association, 6(1), 1-44.

Acemoglu, D., S. Johnson, and J. Robinson (2005): "Institutions as the Fundamental Cause of Long-Run Growth," in Handbook of Economic Growth, ed. by P. Aghion, and S. Durlauf, Amsterdam. North-Holland.

Acemoglu, D., And J. A. Robinson (2006): Economic Origins of Dictatorship and Democracy. Cambridge University Press, New York.

Blonigen, B., And M. Slaughter (2001): "Foreign Affiliate Activity and U.S. Skill Upgrading," Review of Economics and Statistics, 83, 362-376.

Bohn, H., and R. T. Deacon (2000): "Ownership Risk, Investment, and the Use of Natural Resources," The American Economic Review, 90(3), 526549 .

Cardoso, F., and E. Faletto (1979): Dependency and Development in Latin America. University of California Press.

Contsworth, J. H. (1979): "Indispensable Railroads in a Backward Economy: The Case of Mexico," The Journal of Economic History, 39(4), 939960.

(2005): "Structures, Endowments, and Institutions in the Economic History of Latin America," Latin American Research Review, 40(3), 126144.

Cortés Conde, R. (1979): El Progreso Argentino. Sudamericana, Argentina.

Dal Bó, E., And P. DAL Bó (2004): "Workers, Warriors and Criminals: Social Conflict in General Equilibrium," . 
Eaton, J., And M. Gersovitz (1983): "Country Risk: Economic Aspects," in Managing International Risk, ed. by R. J. Herring, Cambridge. Cambridge University Press.

Frieden, J. (1994): "International Investment and Colonial Control: A New Interpretation," International Organization, 48(4).

García Heras, R. (1994): "State Intervention in Urban Passenger Transportation: The Transport Corporation of Buenos Aires, 1939-1962," The Hispanic American Historical Review, 74(1), 83-110.

Haber, S., A. Razo, and N. Maurer (2003): The Politics of Property Rights: Political Instability, Credible Commitments, and Economic Growth in Mexico, 1876-1929. Cambridge University Press, Series on Political Economy of Institutions and Decisions.

Jensen, N. M. (2006): Nation-States and the Multinational Corporation: Political Economy of Foreign Direct Investment. Princeton University Press.

Kindeleberger, C. P. (1969): American Business Abroad: Six Lectures on Direct Investment. Yale University Press, New Haven.

North, D. C., and B. R. Weingast (1989): "Constitutions and Commitment: The Evolution of Institutional Governing Public Choice in Seventeenth-Century England," The Journal of Economic History, 49(4), 803-832.

Olson, M. (1993): "Dictatorship, Democracy and Development," American Political Science Review, 87, 567-76.

Pinto, P. M., And S. M. Pinto (2008): "The Politics of Investment: Partisanship and the Sectoral Allocation of Foreign Direct Investment," Economics $\mathscr{E}$ Politics, 20(2), 216-254.

Rogowski, R. (1986): "Trade and the Variety of Democratic Institutions," International Organization, 41(2), 2003-23. 
- (1987): "Political Cleavages and Changing Exposure to Trade," American Political Science Review, 81(4), 1121-37.

— (1989): Comerce and Coalitions: How Trade Affects Domestic Political Aligmnments. Princeton University Press.

Sanz Fernandez, J. (1998): Historia de los Ferrocarriles de Iberoamerica, 1837-1995. Centro de Estudios y Experimentación de Obras Públicas (CEDEX), Madrid.

Schiffer, M., And B. Weder (2000): "Catastrophic Political Risk versus Creeping Expropriation: What determines Private Infrastructure Investment in Less Developed Countries?," World Bank.

Stolper, W., and P. A. Samuelson (1941): "Protection and Real Wages," Review of Economic Studies, 9, 58-73.

Summerhill, W. (2006): "The Development of Infraestructure," in The Cambridge economic history of Latin America, ed. by V. Bulmer-Thomas, J. H. Coatsworth, and R. Cortés-Conde, New York. Cambridge University Press.

Vernon, R. (1971): Sovereignty at Bay, The Multinational Spread of United States Enterprises. Basic Books, New York.

\section{Appendices}

\section{A Determination of $X^{A R W}(\varphi)$}

The existence of the railroad, and the negotiated fee, imply a change $\widehat{z}$ in the "net price" of good $X$. The implications for factor prices were derived above: given the assumption that good $X$ is relatively land-intensive, $\left(\gamma_{S}>\gamma_{X}\right.$, with $\gamma_{i}$ the labor share in sector $i$ ) the standard Stolper-Samuelson result applies: if 
$\widehat{z}>0, \widehat{w}-\widehat{z}>0, \widehat{t}<0$. The output movements are determined by the factordemand equations (where a hat over a variable indicates the proportional change of the variable):

$$
\begin{aligned}
& \widehat{L}=0=\lambda_{L X} \widehat{L}_{X}+\lambda_{L S} \widehat{L}_{S} \\
& \widehat{T}=0=\lambda_{T X} \widehat{T}_{X}+\lambda_{T S} \widehat{T}_{S}
\end{aligned}
$$

where $\lambda_{A i}=A_{i} / A$ is the share of sector $i$ in the total use of factor $A$.If $\widehat{A}_{i}$ is the proportional change of the use of factor $A$ in sector $i$, and production functions have a Cobb-Douglas form, the changes in the demand for factors are given by:

$$
\widehat{A}_{i}=\widehat{y}_{i}-\left(\widehat{h}_{A}-\widehat{p}_{i}\right)
$$

where $\widehat{y}_{i}$ is the proportional change in the output of good $i, \widehat{p}_{i}$ the proportional change in the price of $i$, and $\widehat{h}_{A}$ the change in the reward of factor $A$.

Then:

$$
\begin{aligned}
& 0=\lambda_{L X} \widehat{y}_{X}+\lambda_{L S} \widehat{y}_{S}-\lambda_{L X}(\widehat{w}-\widehat{z})-\lambda_{L S} \widehat{w} \\
& 0=\lambda_{T X} \widehat{y}_{X}+\lambda_{T S} \widehat{y}_{S}-\lambda_{T X}(\widehat{t}-\widehat{z})-\lambda_{T S} \widehat{t}
\end{aligned}
$$

It can be noted that. given the results on $\widehat{w}, \widehat{t}$, if $\widehat{z}>0$ :

$$
\begin{aligned}
\lambda_{L X}(\widehat{w}-\widehat{z})+\lambda_{L S} \widehat{w} & =\phi_{w}<0 \\
\lambda_{T X}(\widehat{t}-\widehat{z})+\lambda_{T S} \widehat{t} & =\phi_{t}>0
\end{aligned}
$$

The determinant of the system of factor demands is: $\Delta=\lambda_{L X} \lambda_{T S}-\lambda_{T X} \lambda_{L S}$ Now: $\lambda_{A i}=\frac{A_{i}}{A}=\frac{h_{A} A_{i}}{h_{A} A}=\frac{h_{A} A_{i}}{p_{i} y_{i}} \frac{p_{i} y_{i}}{h_{A} A}$ so that:

$$
\Delta=\frac{w L}{z y_{X}} \frac{t T}{p_{S} y_{S}}\left(\gamma_{X}\left(1-\gamma_{S}\right)-\left(1-\gamma_{X}\right) \gamma_{S}\right)
$$

Clearly:

$$
\operatorname{sgn} \Delta=\operatorname{sgn}\left(\gamma_{X-} \gamma_{S}\right)<0 \text { given the assumptions }
$$

Then: solving:

$$
\begin{aligned}
\widehat{y}_{X} & =\frac{1}{\Delta}\left(\phi_{w} \lambda_{T S}-\phi_{t} \lambda_{L S}\right)>0 \\
\widehat{y}_{S} & =\frac{1}{\Delta}\left(\phi_{t} \lambda_{L X-} \phi_{w} \lambda_{T X}\right)<0
\end{aligned}
$$

These equations establish the changes in output as a function of $z$, the 
"producer" price of good $X$.

Those changes can be (through tedious but straighforward calculations) expressed in terms of "primitives": the parameters $\gamma_{X}, \gamma_{S}$, and the initial shares of the sectors in the value of output (which, with more computations, can be derived from factor endowments): $\mu_{i}=\frac{p_{i} y_{i}}{\sum_{j=X, S} p_{j} y_{j}}$, with $i=X, S$, and $p_{i}$ producer's prices.

Then:

$$
\lambda_{L X}=\frac{w L_{X}}{w L}=\frac{\gamma_{X} \mu_{X}}{\gamma_{X} \mu_{X}+\gamma_{S} \mu_{S}}
$$

and a similar expression for the share of $X$ in the use of land.

Also:

$$
\begin{gathered}
\phi_{w}=\lambda_{L X} \frac{1-\gamma_{X}}{\gamma_{X}-\gamma_{S}}+\lambda_{L S} \frac{1-\gamma_{S}}{\gamma_{X}-\gamma_{S}} \\
=\frac{1}{\gamma_{X} \mu_{X}+\gamma_{S} \mu_{S}} \frac{1}{\gamma_{X}-\gamma_{S}}\left(\gamma_{X} \mu_{X}\left(1-\gamma_{X}\right)+\gamma_{S} \mu_{S}\left(1-\gamma_{S}\right)\right) \\
\phi_{t}=\lambda_{T X} \frac{\gamma_{X}}{\gamma_{S}-\gamma_{X}}+\lambda_{T S} \frac{\gamma_{S}}{\gamma_{S}-\gamma_{X}} \\
=\frac{1}{\left(1-\gamma_{X}\right) \mu_{X}+\left(1-\gamma_{S}\right) \mu_{S}} \frac{1}{\gamma_{S} \gamma_{X}}\left(\gamma_{X} \mu_{X}\left(1-\gamma_{X}\right)+\gamma_{S} \mu_{S}\left(1-\gamma_{S}\right)\right)
\end{gathered}
$$

The determinant of the system that determines the output changes $\widehat{y}_{i}$ is:

$$
\Delta=\left(\gamma_{X} \mu_{X}+\gamma_{S} \mu_{S}\right)^{-1}\left(\left(1-\gamma_{X}\right) \mu_{X}+\left(1-\gamma_{S}\right) \mu_{S}\right)^{-1}\left(\gamma_{X}-\gamma_{S}\right)
$$

Which implies:

$$
\widehat{y}_{X} / \widehat{z}=\frac{1}{\left(\gamma_{X}-\gamma_{S}\right)^{2}}\left(\gamma_{X} \mu_{X}\left(1-\gamma_{X}\right)+\gamma_{S} \mu_{S}\left(1-\gamma_{S}\right)\right)=\epsilon
$$

This corresponds to the standard Rybcynski result that the output of good $X$ increases unambiguously with the producer price of the good (and an analogous expression would show that production of $S$ would fall as $z$ increases).

Equation (19) allows us to derive the following expression of the production of $X$ once the railway has been established: 


$$
X(A R W)=\left(1+\epsilon \frac{(\alpha-\varphi)}{1-\alpha}\right) X(B R W)
$$

where the expressions $B R W, A R W$ indicate, respectively, "before the railway" and "after the railway".

\section{B Proof of proposition 3}

We have to prove as well the existence of a range of values for $\varphi$ such as expropriation will take place. This is equivalent to show the existence of values of $\varphi$ such as $\varphi_{1 D}>0$ in the case of a Democracy and $\varphi_{1 A}<\alpha$ in the case of an oligarchy. From equation 10 we see that this is always the case for

$$
\alpha>\frac{(1-\beta) \mu}{\left|\widehat{\gamma_{1}}\right| w(B R W)-(1-\beta) \mu}
$$

when the political regime is a Democracy. Similarly, we obtain from equation 7 that the possibility of expropriation requires

$$
\alpha>\frac{(1-\beta) \mu}{r(B R W) \hat{\gamma_{2}}+(1-\beta) \mu}
$$

Observe that the bounds (21) and (22) are both lower than unity. More importantly, notice that both establish the following conditions:

Condition 2 The government chooses expropriation, if feasible, when $\alpha$ satisfies

$$
\alpha>\frac{(1-\beta) \mu}{2\left|\widehat{\gamma_{1}}\right| w(B R W)+(1-\beta) \mu}
$$

if the political regime is a Democracy

and

Condition 3 The government chooses expropriation, if feasible, when a satisfies

$$
\alpha>\frac{(1-\beta) \mu}{r(B R W) \hat{\gamma_{2}}+(1-\beta) \mu}
$$

if the political regime is an oligarchy.

We can now establish the existence of intervals $Z_{1}-Z_{5}$. 
1. $Z_{1}$ corresponds to values of $\varphi$ such as $\varphi<\operatorname{Min}\left(\alpha, \varphi_{1 A}, \varphi_{1 D}\right)$. This requires the satisfaction of conditions 1 and 2. Condition 1 establishes the existence of $\varphi$ such that the investor wishes to undertake the project. Condition 2 establishes the existence of $\varphi$ such as expropriation takes places in a Democracy. Proposition 1 provides the conditions for $\varphi_{1 A}<$ $\varphi_{1 D}$ which implies the existence of values of $\varphi$ such as expropriation takes place only under Democracy.

2. $Z_{2}$ corressponds to values of $\varphi$ such as $\varphi \in\left(\operatorname{Max}\left[\varphi_{1 A}, \varphi_{1 D}\right], \alpha\right)$. This requires the satisfaction of conditions 1 and 3. Proposition 1 provides the conditions for $\varphi_{1 A}>\varphi_{1 D}$

3. $Z_{3}$ corresponds to values of $\varphi$ such as $\varphi \in\left(\varphi_{1 A}, \operatorname{Min}\left[\alpha, \varphi_{1 D}\right]\right)$. This requires the satisfaction of conditions 1,2 and 3 .

4. $Z_{4}$ corresponds to values of $\varphi$ such as $\varphi \in\left(\varphi_{1 D}, \operatorname{Min}\left[\alpha, \varphi_{1 A}\right]\right)$. This simply requires condition 1 .

\section{Foreign Investment under Export Taxes}

We analyze the investment decision when the government can implement export taxes. Let $\psi^{\text {taxes }}$ be the probability of a social state allowing for export taxes $\left(\tau^{X}\right)$. Let us assume that there is a maintenance cost which for simplicity we assume to be equivalent to a fixed cost (F). Implementing $\tau^{X}$ will bring $\mathrm{X}$ to the initial level $(X(A R W))$. The continuation value associated with investment when taxing is possible $\left(W^{F I}(X T)\right)$ is $W^{F I}(X T)=$ $\psi^{\text {taxes }} V^{F I}(G)+\left(1-\psi^{\text {taxes }}\right) V^{F I}(B)$, where:

$$
\begin{aligned}
V^{F I}(B) & =\varphi\left(1+\epsilon \frac{\alpha-\varphi}{1-\alpha}\right) X^{B R W}-F+\beta W^{F I}(X T) \\
V^{F I}(G) & =\varphi X^{B R W}-F
\end{aligned}
$$

Therefore,

$$
W^{F I}(X T)=\frac{\varphi X^{B R W}\left(\psi^{\text {taxes }}\left(1-\left(1+\epsilon^{\alpha-\varphi}\right)\right)+\left(1+\epsilon \frac{\alpha-\varphi}{1-\alpha}\right)\right)}{1-\left(1-\psi^{\text {taxes }}\right) \beta}-F
$$

Investment takes place if $W^{F I}(X T)>\frac{i K}{1-\beta}$. Using $\kappa=\frac{K}{X^{A R W}}, \frac{K}{X^{B R W}}=$ $\kappa\left(1+\epsilon \frac{\alpha-\varphi}{1-\alpha}\right)$. It can therefore be shown that the foreign investor requires 


$$
\varphi \geq \kappa\left(i+\frac{F}{K}\right) \frac{\left(1-\left(1-\psi^{\text {taxes }}\right) \beta\right)\left(1+\epsilon \frac{\alpha-\varphi}{1-\alpha}\right)}{\psi^{\text {taxes }}+\left(1-\psi^{\text {taxes }}\right)\left(1+\epsilon \frac{\alpha-\varphi}{1-\alpha}\right)}
$$

This shows that investment takes place for higher efficiency levels $\left(\frac{1}{\kappa}\right)$, lower maintenance costs $(\mathrm{F})$ and railway capacity $(\mathrm{K})$, and lower frequency of states where taxes can take place.

Notice as well that if $F>\varphi X^{B R W}$, the investor abandons the railway which may eventually be nationalized. In this case, $V^{F I}(G)=0$

\section{Proposition 4}

There are two cases to be considered:

D.1 $\phi_{1 A}^{\prime}<\alpha$

Equation 18 becomes:

$$
\frac{\varphi_{1 A} X^{A R W}\left(\varphi_{1 A}\right)}{1-\beta}<\frac{(1-\psi) \alpha X^{A R W}(\alpha)}{1-(1-\psi) \beta} .
$$

That is using (12) and (7),

$\frac{\mu(1-\alpha)}{r(B R W) \hat{\gamma_{2}}}\left[1+\frac{\epsilon \alpha}{1-\alpha}-\frac{\mu(1-\beta) \epsilon}{r(B R W) \hat{\gamma_{2}}}\right]<\frac{(1-\psi) \alpha}{1-(1-\psi) \beta}+\frac{(1-\psi) \eta}{(1-\alpha)(1-(1-\psi) \beta)}$

This is clearly satisfied for $\mu=0$. For $\mu<\frac{1}{2(1-\beta) \epsilon}+\frac{\alpha}{2(1-\beta)(1-\alpha)}$, the left hand side is increasing in $\mu$ which means that there is a value of $\mu=\bar{\mu}$ beyond which inducing expropriation is no longer preferred by the foreign investor. This threshold is:

$$
\overline{\mu_{1}}=\frac{\Upsilon_{1}\left(\epsilon, \hat{\gamma_{2}}, \alpha, \psi, \beta\right)+\left[\Upsilon_{1}\left(\epsilon, \hat{\gamma_{2}}, \alpha, \psi, \beta\right)^{2}-4 \Phi_{1}\left(\epsilon, \hat{\gamma_{2}}, \alpha, \psi, \beta\right) \Gamma_{1}\left(\epsilon, \hat{\gamma_{2}}, \alpha, \psi, \beta\right)\right]^{\frac{1}{2}}}{2 \Gamma_{1}\left(\epsilon, \hat{\gamma_{2}}, \alpha, \psi, \beta\right)}
$$

where, 


$$
\begin{aligned}
\Upsilon_{1} & =\frac{1-\alpha(1-\epsilon)}{r(B R W) \hat{\gamma}_{2}} \\
\Gamma_{1} & =\frac{(1-\alpha)(1-\beta) \epsilon}{\left(r(B R W) \hat{\gamma_{2}}\right)^{2}} \\
\Phi_{1} & =\frac{1-\psi}{1-(1-\psi) \beta}\left(\alpha+\frac{\eta}{1-\alpha}\right)
\end{aligned}
$$

\section{D.2 $\phi_{1 A}^{\prime} \geq \alpha$}

Equation 18 becomes:

$$
\frac{\varphi_{1 A} X^{A R W}\left(\varphi_{1 A}\right)}{1-\beta}<\frac{(1-\psi) \varphi_{1 A}^{\prime} X^{A R W}\left(\varphi_{1 A}^{\prime}\right)}{1-(1-\psi) \beta} .
$$

That is using (16),

$$
\frac{\varphi_{1 A}}{1-\beta}\left(1+\epsilon \frac{\alpha-\varphi_{1 A}}{1-\alpha}\right)<\frac{(1-\psi)}{1-(1-\psi) \beta} \varphi_{1 A}^{\prime}\left(1+\epsilon \frac{\alpha-\varphi_{1 A}^{\prime}}{1-\alpha}\right)
$$

This condition is satisfied for $\mu=0$. Also, the right hand side is increasing in $\varphi^{\prime}$, which is itself decreasing in $\mu$. We can also show that the left hand side is increasing in $\mu$ as long as $\mu<\frac{1}{2(1-\alpha)(1-\beta)}$. Given this, it is clear that (23) is satisfied for sufficiently low values of $\mu$. The threshold is implicity given by:

$$
\overline{\mu_{2}}=\frac{\Upsilon_{2}\left(\epsilon, \hat{\gamma_{2}}, \alpha, \psi, \beta\right)+\left[\Upsilon_{2}\left(\epsilon, \hat{\gamma_{2}}, \alpha, \psi, \beta\right)^{2}-4 \Phi_{2}\left(\epsilon, \hat{\gamma_{2}}, \alpha, \psi, \beta\right) \Gamma_{2}\left(\epsilon, \hat{\gamma_{2}}, \alpha, \psi, \beta\right)\right]^{\frac{1}{2}}}{2 \Gamma_{2}\left(\epsilon, \hat{\gamma_{2}}, \alpha, \psi, \beta\right)}
$$

Where:

$$
\begin{aligned}
\Upsilon_{2}\left(\epsilon, \hat{\gamma_{2}}, \alpha, \psi, \beta\right)= & \frac{1-\alpha(1-\epsilon)}{r(B R W) \hat{\gamma_{2}}}-\frac{\alpha^{2}\left(\frac{1-(1-\psi) \beta}{(1-\psi)(1-\beta)}\right)\left(\frac{\psi}{1-\psi} \frac{1}{\hat{\gamma}_{2} r(B R W)}\right)}{(1-\beta)}+ \\
& \frac{(1-\alpha)(1-\psi)+\alpha \epsilon(1-\psi)-(1-\psi)\left(\alpha\left(\frac{1-(1-\psi) \beta}{(1-\psi)(1-\beta)}\right)\right)}{\psi r(B R W)(1-(1-\psi) \beta)} \\
\Gamma_{2}\left(\epsilon, \hat{\gamma_{2}}, \alpha, \psi, \beta\right)= & \frac{1-\alpha}{r(B R W) \hat{\gamma_{2}}}\left[\frac{1-\beta}{r(B R W) \hat{\gamma_{2}}}+\frac{1}{(1-(1-\psi) \beta) r(B R W)}\right] \\
\Phi_{2}\left(\epsilon, \hat{\gamma_{2}}, \alpha, \psi, \beta\right)= & \frac{\alpha}{1-\alpha}\left[1+\frac{\alpha}{1-\beta}\left(\epsilon-\frac{1-(1-\psi) \beta}{(1-\psi)(1-\beta)}\right)\right]
\end{aligned}
$$

